\title{
Pancreatitis in Finland between 1970 and 1989
}

\author{
M Jaakkola, I Nordback
}

Abstract

The incidence and mortality from pancreatitis in Finland between 1970 and 1989 were studied and compared with the alcohol consumption in the country and with the incidence of liver cirrhosis and gall stone disease. Hospital discharge data were obtained from the Finnish National Agency for Welfare and Health, the causes of deaths from the Finnish State Statistics, and annual alcohol consumption from the Finnish State Alcohol Company. There were 56353 hospital treatment periods because of pancreatitis. The incidence of pancreatitis discharges increased from 46.6 to $73.4 / 100000 /$ year. In men it increased from 59.1 to 113.4 , but in women it remained unchanged (mean 35.0). The incidence of pancreatitis discharges correlated with the alcohol consumption in Finland $(r=0.78$, $p=0.0001$ ). The incidence of pancreatitis discharges correlated in men, but not in women, with the incidence of liver cirrhosis $(r=0.81$, $\mathbf{p}=\mathbf{0 . 0 0 0 1}$ ). In women, but not in men, the incidence of pancreatitis discharges correlated with the incidence of gall stone disease discharges $(r=0.77, p=0.0001)$. The incidence of discharges due to haemorrhagic pancreatitis and pancreatic abscess doubled in men and remained unchanged in women. Pancreatitis death rate decreased from $\mathbf{5 . 9 \%}$ (men $\mathbf{4 . 8 \%}$, women $7.0 \%$ ) to $2.6 \%$ (men $2.4 \%$, women $\mathbf{2 \cdot 7 \% ) . ~}$

(Gut 1993; 34: 1255-1260)
Despite numerous studies published on the incidence and mortality of pancreatitis in various hospitals, only a few epidemiological studies on large populations have been carried out. The recent and, according to our knowledge, the only previous nationwide survey from Scotland showed an appreciable increase in the incidence of pancreatitis between 1961 and 1985.' Gall stone disease is the most common cause of pancreatitis in Scotland. ${ }^{12}$ In comparison, alcohol is the most common cause of pancreatitis in patients in Finland. ${ }^{34}$ In Finland alcohol consumption has shown an increase up to the 1990 s, which is in contrast with other European countries. ${ }^{5}$ This study was carried out to examine the two decade trends in the incidence and death from pancreatitis, and to evaluate the relations between the occurrence of pancreatitis and alcohol consumption, liver cirrhosis, and gall stone disease in Finland. Furthermore, as the amount of alcohol consumed before pancreatitis correlates with the severity markers of the disease in patients with the first acute alcoholic pancreatitis episode, ${ }^{6}$ the correlation between the alcohol consumption in Finland and the occurrence of severe pancreatitis in the country was also studied.

\section{Methods}

ALCOHOL CONSUMPTION

In Finland the selling of all alcoholic beverages is
Department of Clinical Medicine, University of Tampere, Tampere, Finland

M Jaakkola

I Nordback

Correspondence to:

Dr M Jaakkola, Department of Clinical Medicine, University of Tampere, PO Box 607, SF 33101 Tampere, Finland.

Accepted for publication 5 January 1993

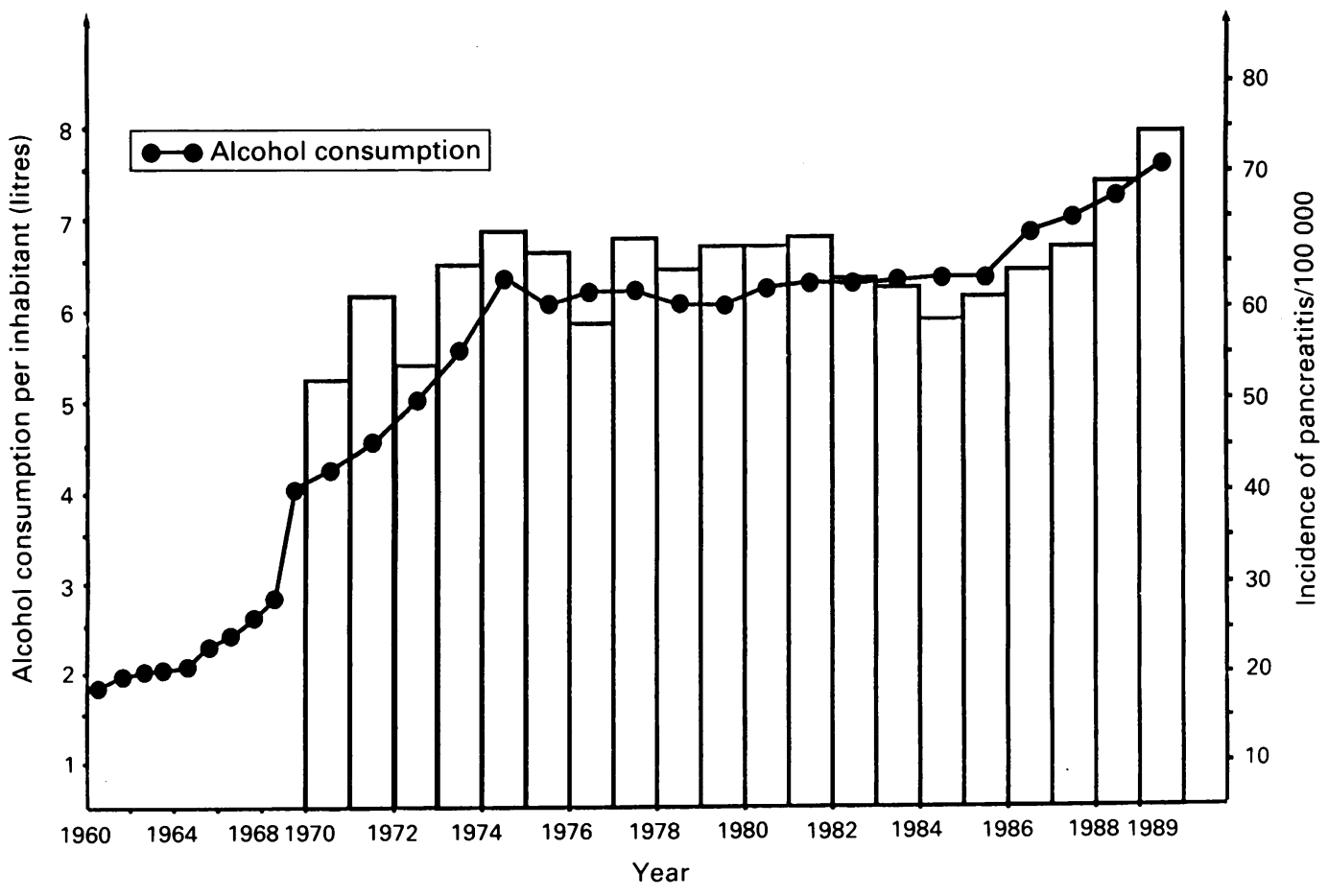

Figure 1: Annual alcohol consumption (litres of ethanol per inhabitant) between 1960 and 1989 and annual incidence of pancreatitis discharges (ICD code 577) in Finland between 1970 and 1989. 


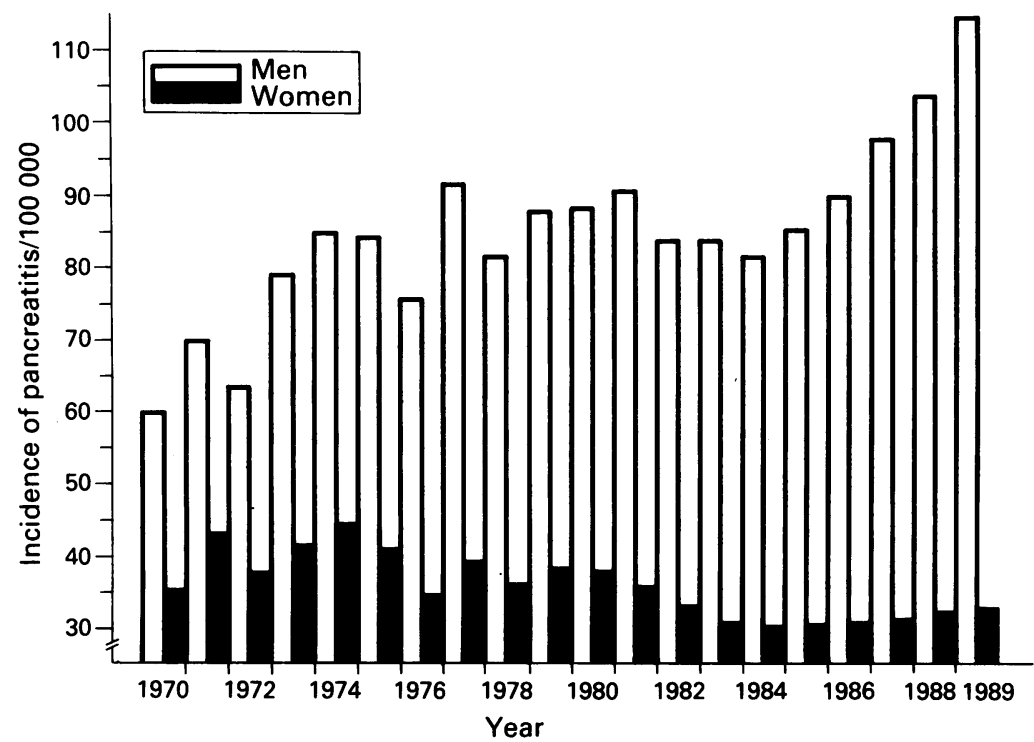

Figure 2: Incidence of pancreatitis discharges (ICD code 577) in men and women in Finland between 1970 and 1989. population in Finland increased from 4598300 in 1970 to 4974400 in 1989 , the average annual increase being $0 \cdot 4 \% .^{7}$ The mean age of the population increased from 32 to 35 years in men and from 35 to 39 years in women during this period. Approximately $60 \%$ of the population live in urban areas.

\section{EPISODES OF PANCREATITIS}

Annual discharges with the diagnosis of pancreatitis (ICD Code 577) during 1970-89 were obtained from the statistics of the Finnish National Agency for Welfare and Health. These statistics account for all discharges from all the Finnish hospitals after a stay in hospital for more than one day. From 1977 the diagnoses of acute and chronic pancreatitis could be obtained separately. Also discharges because of acute haemorrhagic necrotising pancreatitis and pancreatic abscess could be identified separately from 1977 onwards. These diagnoses were considered to represent severe acute pancreatitis. Incidences were calculated as the number of annual discharges in a population of 100000 in each age and sex groups. For comparison, the number of discharges because of liver cirrhosis (ICD code 571) and gall stone disease (ICD code 574) were also obtained, and the incidences were calculated as expressed above.

1960-89. The consumption was expressed as litres of ethanol per inhabitant. About $40 \%$ of alcoholic beverages sold through retail outlets was spirits and $45 \%$ was beer in $1989 .^{5}$

\section{POPULATION}

The population of Finland is registered on the census list based statistics that are updated annually. According to the official statistics the

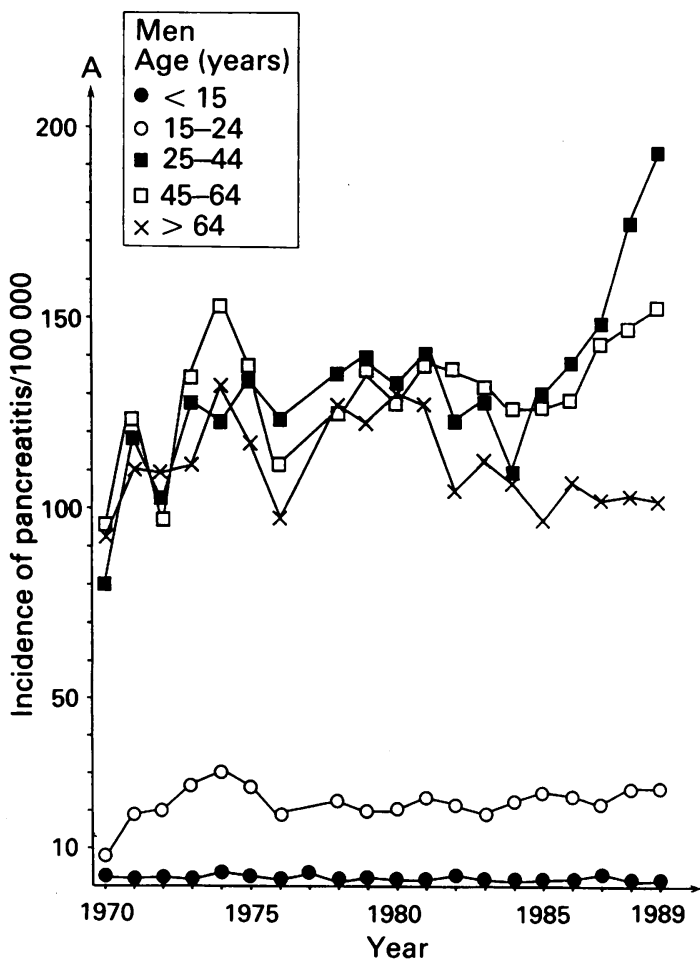




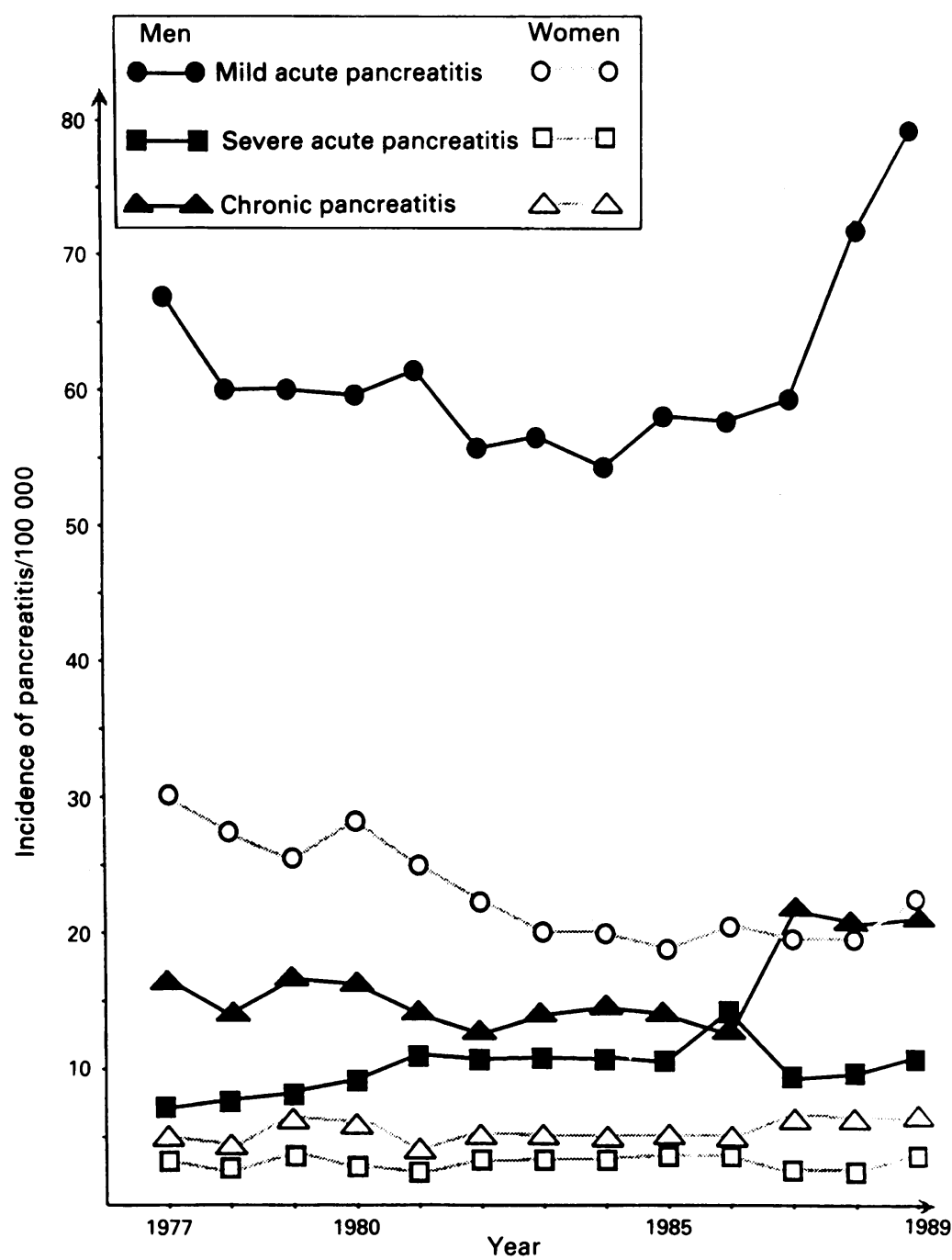

Figure 4: Incidence of discharges because of acute mild and acute severe pancreatitis, and chronic pancreatitis in men and women in Finland between 1977 and 1989. and 1987-9, but remained comparatively unchanged from 1975 to 1986 . The increase took place only in men, whereas in women the incidence slightly decreased (Fig 2).

In men $60-70 \%$ of discharges were seen among adults between 25-64 years of age (Fig 3A). The increase in the overall incidence of pancreatitis discharges was seen predominantly in this age group (Fig 3A). In women about half of the discharges were seen among the patients over 64 years of age (Fig 3B). The decrease in the incidence of pancreatitis discharges in women also occurred predominantly in this age group (Fig 3B).

\section{INCIDENCE OF CHRONIC PANCREATITIS}

Between 1977-89 it was possible to differentiate between discharges as a result of acute and chronic pancreatitis. The distribution of discharges between these two diagnoses was relatively unchanged during this period (Fig 4). The incidence of chronic pancreatitis discharges increased from 10.4 to 13.4 (increase $26 \%$ ) between 1977-89. Approximately $80 \%$ of chronic pancreatitis discharges were men.

\section{INCIDENCE OF SEVERE ACUTE PANCREATITIS}

Between 1977-89 discharges due to haemorrhagic necroticing pancreatitis and pancreatic abscess (together considered to represent severe pancreatitis) could be differentiated from mild pancreatitis. The overall incidence of severe pancreatitis was $5 \cdot 3 / 100000 /$ year and accounted for $12.3 \%$ of all pancreatitis discharges. In men the incidence of severe pancreatitis discharges was $6 \cdot 6 / 100000 /$ year in 1977 and $11 \cdot 3 / 100000 /$ year in 1989. The proportion of severe episodes from all pancreatitis discharges in men increased from $8 \cdot 1 \%$ in 1977 to $13.4 \%$ in 1981 and remained at an average of $14.0 \%$ during the 1980 s (Fig 4). In women the incidence of severe pancreatitis discharges was $3 \cdot 6 / 100000 /$ year in 1977 and $3 \cdot 4 / 100000 /$ year in 1989 , the proportion of severe episodes from all pancreatitis discharges remaining fairly stable, an average of $11 \cdot 1 \%$ (Fig 4 ).

\section{Results}

ALCOHOL CONSUMPTION

Alcohol consumption per inhabitant increased from 1.9 to 7.6 litres (fourfold increase) during 1960-89 (Fig 1). A sharp rise in consumption occurred in 1969, when the sale of strong beer (3.8\% alcohol content) was allowed in general stores. ${ }^{5}$ Between 1970-89 alcohol consumption increased during 1970-4 and 1984-9, but was relatively stable during $1975-83$ (Fig 1).

\section{INCIDENCE OF PANCREATITIS}

There were 56353 discharges after a stay in hospital because of pancreatitis in Finland between 1970-89. The incidence of pancreatitis discharges in the whole population increased from 46.6 to $73 \cdot 4 / 100000$ /year (by $58 \%$ ) during the two decade study period (Fig 1). The incidence increased remarkably during 1970-4

\section{MORTALITY FROM PANCREATITIS}

The annual number of deaths from pancreatitis decreased from 132 to 52 from 1970 to 1989 ,

Annual number of pancreatitis deaths $(P)$, death rate in population per $100000(D)$, and death rate in pancreatitis patients (case mortality per 100)(C) in Finland between 1970 and 1989

\begin{tabular}{|c|c|c|c|c|c|c|c|c|c|}
\hline \multirow[b]{2}{*}{ Period } & \multicolumn{3}{|c|}{ Men } & \multicolumn{3}{|c|}{ Women } & \multicolumn{3}{|c|}{ Total } \\
\hline & $P$ & $D$ & $C$ & $P$ & $D$ & $C$ & $P$ & $D$ & $C$ \\
\hline $\begin{array}{l}1970-1 \\
1972-3 \\
1974-5 \\
1976-7 \\
1978-9 \\
1980-1 \\
1982-3 \\
1984-5 \\
1986-7 \\
1988-9\end{array}$ & $\begin{array}{l}68 \\
58 \\
75 \\
69 \\
67 \\
86 \\
70 \\
56 \\
75 \\
62\end{array}$ & $\begin{array}{l}3 \cdot 1 \\
2 \cdot 6 \\
3 \cdot 3 \\
3 \cdot 0 \\
2 \cdot 9 \\
3 \cdot 7 \\
3 \cdot 0 \\
2 \cdot 4 \\
3 \cdot 1 \\
2 \cdot 6\end{array}$ & $\begin{array}{l}4 \cdot 8 \\
3 \cdot 7 \\
3 \cdot 9 \\
3 \cdot 7 \\
3 \cdot 5 \\
4 \cdot 2 \\
3 \cdot 6 \\
2 \cdot 8 \\
3 \cdot 4 \\
2 \cdot 4\end{array}$ & $\begin{array}{l}65 \\
67 \\
62 \\
41 \\
36 \\
36 \\
39 \\
32 \\
29 \\
23\end{array}$ & $\begin{array}{l}2.7 \\
2.8 \\
2.6 \\
1.7 \\
1.5 \\
1.9 \\
1.6 \\
1.3 \\
1.1 \\
0.9\end{array}$ & $\begin{array}{l}7 \cdot 0 \\
7 \cdot 1 \\
6 \cdot 3 \\
4 \cdot 8 \\
4 \cdot 0 \\
4 \cdot 1 \\
5 \cdot 0 \\
4 \cdot 4 \\
3 \cdot 7 \\
2 \cdot 7\end{array}$ & $\begin{array}{l}67 \\
63 \\
69 \\
55 \\
52 \\
61 \\
55 \\
44 \\
52 \\
43\end{array}$ & $\begin{array}{l}2.9 \\
2.7 \\
3.0 \\
2.4 \\
2.2 \\
2.6 \\
2.3 \\
1.9 \\
2.1 \\
1.8\end{array}$ & $\begin{array}{l}5 \cdot 9 \\
5 \cdot 4 \\
5 \cdot 1 \\
4 \cdot 3 \\
3 \cdot 8 \\
4 \cdot 2 \\
4 \cdot 3 \\
3 \cdot 6 \\
3 \cdot 6 \\
2 \cdot 6\end{array}$ \\
\hline $\begin{array}{l}\text { Total } \\
\text { (mean) }\end{array}$ & 69 & $3 \cdot 0$ & $3 \cdot 6$ & 43 & 1.8 & 4.9 & 56 & $2 \cdot 4$ & $4 \cdot 3$ \\
\hline
\end{tabular}


Figure 5: Incidence of discharges because of liver cirrhosis (ICD code 571) in various age and sex groups in Finland between 1970 and 1989.

Figure 6: Incidence of discharges because of gall stone disease (ICD code 574) in various age and sex groups in Finland between 1970 and 1989.

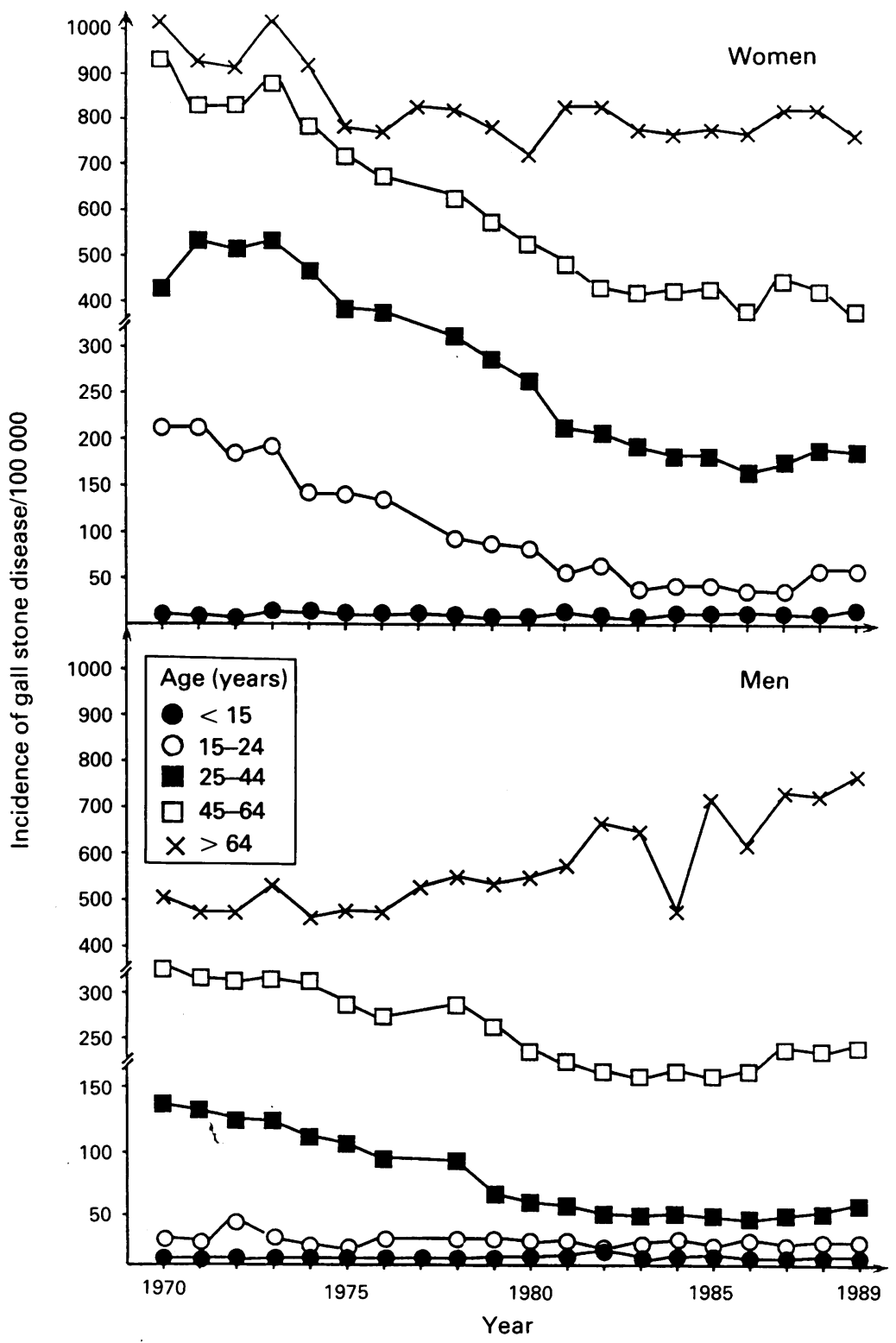

respectively (decrease 61\%). During this period the death rate from pancreatitis in the population decreased by $67 \%$ (Table). The mortality decreased continuously in women, the decrease in the mortality in men being less prominent since 1974 (Table).

CORRELATION WITH ALCOHOL CONSUMPTION, LIVER CIRRHOSIS, AND GALL STONE DISEASE There was a strong positive correlation between the incidence of pancreatitis discharges and the alcohol consumption in Finland $(r=0.78, \mathrm{p}=$ 0.0001 ). Alcohol consumption in Finland also correlated significantly with the incidence of chronic pancreatitis discharges $(r=0.74, \mathrm{p}=$ 0.004).

The incidence of discharges because of liver cirrhosis in Finland increased from 26.4 to 49.4 / 100000 /year (increase 87\%) from 1970 to 1989 (Fig 5). Approximately $65 \%$ of discharges were men, and the incidence was highest among men aged 45-64 years (Fig 5). The most noticeable increase in discharges as a result of liver cirrhosis occurred between 1986-9. The alcohol consumption in Finland correlated significantly with the incidence of liver cirrhosis discharges $(r=0.65, p=0.002)$. The incidence of liver cirrhosis discharges correlated significantly with the incidence of pancreatitis discharges in men $(r=0.81, p=0.0001)$, but not in women.

The incidence of discharges because of gall stone disease decreased from $368 \cdot 4$ to $247 \cdot 4$ / 100000 (decrease 33\%) from 1970 to 1989 (Fig 6). By comparison with other age and sex groups, 65 years or older men showed an increased incidence of discharges because of gall stone disease beginning from the late 1970s (Fig 6). There was a significant positive correlation between the incidence of gall stone disease discharges and the incidence of pancreatitis discharges in women $(r=0.77, \mathrm{p}=0.0001)$, but not in men.

\section{Discussion}

Although acute and chronic pancreatitis are considered common diseases in many Western areas, surprisingly few epidemiological studies on large populations have been reported..$^{910}$ The official statistics in Finland have some major advantages for performing a nationwide epidemiological study. Firstly, exact data on the overall population can be obtained from the annually updated census list based statistics. Secondly, the hospital discharges with various diagnoses from all the Finnish hospitals are recorded annually. These discharge statistics can also be obtained separately in men and women in various age groups. Also the number of deaths with various diagnoses can be obtained from the annually updated national statistics on the causes of death. Furthermore, as there is only one institution for controlling and selling of all alcoholic beverages in Finland, the alcohol consumption in the country can be evaluated fairly reliably. There are still some pitfalls, however, in this kind of epidemiological study. There may be errors in medical records or in transferring information from medical records to discharge 
register files. According to a previous study from Finland, however, the accuracy of the discharge data is good, being about $90 \%$ for pancreatitis. ${ }^{11}$ Because the recording system has remained unchanged throughout the study period, any changes in the data are probably not a result of errors in registration.

Furthermore, the basic diagnostic test for pancreatitis has been a measurement of serum or urine amylase activity throughout the study period. Unfortunately, acute and chronic pancreatitis could not be separated in the discharge statistics before 1977. Also, by comparison with Scotland,' regional differences could not be studied from the Finnish discharge data.

According to this survey pancreatitis has been a comparatively common disease in Finland, the mean annual incidence of acute pancreatitis discharges being about $50 / 100000$, and in men in 1989 even $90 / 100000$. This is noticeably more than in the previous European series from Nottingham (14/100000/year), ${ }^{12}$ Bristol (7/ $100000 /$ year), ${ }^{13}$ Göttingen (21/100000/year), ${ }^{14}$ Glasgow (15/100000/year),' Copenhagen (28/ $100000 /$ year $),{ }^{10}$ and even more than in the previous survey from Western Australia (60/ 100000 /year). ${ }^{15}$ Comparison of the incidence of chronic pancreatitis between the various countries is not possible, because such incidences of the disease have been seldom reported.

According to international multicentre surveys by the Sarles' group, chronic pancreatitis has been found predominantly in two types of countries. ${ }^{16}{ }^{17}$ In the first type the diet is high in alcohol, protein, and lipids. France, Italy, Portugal, Switzerland, United States, and Brazil belong to this type. In the second type pancreatitis has been mostly related to malnutrition. The tropical zone of Asia and Africa belong to this type. The incidence of chronic pancreatitis in western France was estimated to average $1 / 100000$ of population in $1970 .{ }^{18}$ More recent population based studies from the Copenhagen area in the early and late 1970s showed 7-10/100000 incidence of chronic pancreatitis. ${ }^{1019}$ According to this study the incidence of discharges because of chronic pancreatitis ranged between 10-15/100000 during 1977-89 in Finland.

The incidence of pancreatitis discharges in Finland greatly increased between 1970-89, especially in men. This increase may be caused by the increased alcohol consumption in the country because most pancreatitis episodes are caused by alcohol in Finnish studies. ${ }^{346}$ It could also be because there was also a noticeable increase in the incidence of liver cirrhosis discharges during this period and most liver cirrhosis cases are also caused by alcohol abuse in Finland. ${ }^{20}$ The discharges due to these two diseases correlated with each other. This is in agreement with the previous findings that the increase in the alcohol consumption in Finland has been particularly attributed to the increase in the number of heavy drinkers, ${ }^{21}$ and that the heavy drinkers are the group that may be more vulnerable to pancreatitis. ${ }^{6223}$

Both acute and chronic pancreatitis seemed to cause less need for a stay in hospital in Finnish women than in Finnish men. Furthermore, in comparison with men the incidence of pancreatitis discharges in women did not increase between 1970 and 1989. As most pancreatitis episodes in men are caused by alcohol abuse, ${ }^{3+6}$ and as the increase in the incidence of pancreatitis discharges took place particularly in men between 25-64 years of age, and this group consumes most of the alcohol in the country, ${ }^{21}$ it is suggested that the increased alcohol consumption and the increased incidence of pancreatitis discharges may have a causal relation. A positive correlation between the alcohol consumption in the study area and the incidence of chronic pancreatitis has previously been seen in the Copenhagen area. ${ }^{19}$

Gall stone disease is the most common cause of pancreatitis in Finnish women. ${ }^{346}$ The diagnostic methods for gall stone disease have changed appreciably during the study period. Until the late 1970 s gall bladder disease had generally been diagnosed by oral cholecystography or intravenous biligraphy, but during the 1980s ultrasonography became the preferred treatment. Moreover, endoscopic and percutaneous cholangiography became, during the 1980s, widely used methods to diagnose bile duct abnormality, including common duct stones. These improvements in diagnosis may also have an effect on the incidence of gall stone disease discharges, and thus could cause a false impression of increase in gall stone disease discharges (Fig 5). But, in fact, the incidence of gall stone disease discharges significantly decreased between 1970-89, except for men 65 years or older. Thus, this decrease in the gall stone disease discharges may be real. This may be because of a decreased gall stone disease rate, which could explain the decrease in pancreatitis discharges in women. More efficient treatment of the gall stone disease and less need for hospital treatment, which results in fewer episodes of recurrent gall stone pancreatitis, may offer a more likely explanation. It is not understood why the incidence of gall stone disease discharges increased in elderly men. In elderly men the incidence of pancreatitis discharges decreased, suggesting that the cause of pancreatitis was most probably because of alcohol or a non-gall stone disease.

The hospital discharge data are based on disease episodes, not on separate patients. Thus, the increased incidence of pancreatitis discharges may be a result of an increased number of recurrent episodes of pancreatitis, and not caused by an increased number of individual patients. In fact, it could easily be thought that increased alcohol consumption could result just in the increased incidence of recurrent pancreatitis. Fewer episodes in recurrent pancreatitis are as severe as in episodes of the first occurrence of pancreatitis. ${ }^{6+25}$ Therefore one would have expected the proportion of severe pancreatitis to decrease. The proportion of severe pancreatitis from all pancreatitis discharges, however, did not decrease, but increased between 1977-89. This would also indirectly suggest that the number of individual patients had increased.

The incidence of severe pancreatitis discharges among adult men also correlated signific- 
antly with the alcohol consumption in the country. Adult men consume most of the alcohol in the country. ${ }^{21}$ Thus it seems that the amount of alcohol consumed may also have an effect on the severity of alcoholic pancreatitis in the total population, as well as in individual subjects. ${ }^{6}$

The incidence of severe pancreatitis discharges doubled in men and remained unchanged in women. The pancreatitis related death rate, however, fell significantly in both sexes during the study period, the decrease being more noticeable in women. This may suggest that the treatment of pancreatitis has improved. The higher death rate in women than in men is probably because of the higher proportion of elderly patients among them. The decrease in pancreatitis related mortality seen in this study has also taken place in Scotland' and Göttingen, ${ }^{14}$ but not in Bristol. ${ }^{13}$

In conclusion, the incidence of pancreatitis has increased, especially in men, in Finland between 1970 and 1989 . This increase is presumably related to the increased alcohol consumption in the country. Mortality from pancreatitis has simultaneously decreased, probably because of improved treatment.

Data were supplied by the Finnish National Agency for Welfare and Health and the Finnish State Alcohol Company. This study has been supported by grants from the Reino Lahtikari Foundation, Paulo Foundation, and the University of Tampere, Finland.

1 Wilson C, Imrie CW. Changing patterns of incidence and mortality from acute pancreatitis in Scotland, 1961-1985. BrF Surg 1990; 77: 731-4.

2 Thomson SR, Hendry WS, McFarlane GA, Davidson AI. Epidemiology and outcome of acute pancreatitis. $\mathrm{Br} \mathcal{F}$ Surg 1987; 74: 398-401.

3 Mero M. Changing aetiology of acute pancreatitis. Ann Chir Gynaecol 1982; 71: 126-9.

4 Puolakkainen $P$, Valtonen V, Paananen A, Schröder T. C-reactive protein (CRP) and serum phospholipase A2 in the assessment of the severity of acute pancreatitis. Gut 1987; 28: 764-71.

5 The Finnish State Alcohol Company. Alcohol Statistical Yearbook 1990. Helsinki, Finland: 1991.
6 Jaakkola M, Sillanaukee P, Löf K, Koivula T, Nordback I The amount of alcohol is an important determinant of the severity of acute alcoholic pancreatitis. Surgery (in press)

7 Health Services. Official Statistics of Finland 1990 XVIII: 86 Year Book of National Board of Health 1970-90. Helsink. of death in Finland. Helsinki, Finland.

9 Cavallini G, Riela A, Brocco G, et al. Epidemiology of acute pancreatitis. In: Beger HG, Buchler M, eds. Acute pancreatitis. In: Beger HG, Buchler M, eds.

10 The Copenhagen Pancreatitis Study Group. Copenhagen pancreatitis study: an interim report from a prospective epidemiological multicenter study. Scand $\mathcal{f}$ Gastroenterol 1981; 16: 305-12.

11 Poikolainen K. Accuracy of hospital discharge data: five alcohol-related diseases. Drug Alcohol Depend 1983; 12: 315-22.

12 Bourke JB, Giggs JA, Ebdon DS. Variations in the incidence and the spatial distribution of patients with primary acute pancreatitis in Nottingham 1969-76. Gut 1979; 20:366-71.

13 Corfield AP, Cooper MJ, Williamson RCN. Acute pancreatitis: a lethal disease of increasing incidence. Gut 1985; 26: 724-9.

14 Lankisch PG, Schirren CA, Schmidt $\mathrm{H}$, et al. Etiology and incidence of acute pancreatitis: a 20-year study in a single institution Digestion 1989; 44: 20-5.

15 Smith DI, Burwill PW. Relationship between male pancreatitis morbidity and alcohol consumption in Western Australia, 1971-84. BrF Addict 1990; 85: 655-8.

16 Sarles H, Cros RC, Bidart JM, and the International Group for the Study of Pancreatic Diseases. A multicenter inquiry into the etiology of pancreatic diseases. Digestion 1979; 19: $110-25$

17 Sarles H. Epidemiology and physiopathology of chronic pancreatitis and the role of the pancreatic stone protein. Clin Gastroenterol 1984; 13: 896-9.

18 Gastard J, Joubaud F, Farbos T, et al. Etiology and course of chronic pancreatitis in Western France. Digestion 1973; 9: chronic

19 Andersen BN, Pedersen NT, Scheel J, Worning H. Incidence of alcoholic chronic pancreatitis in Copenhagen. Scand $\mathcal{J}$

20 Pikkarainen P. Alkoholinkäyttö ja maksakirroosi (Alcohol consumption and liver cirrhosis). Duodecim 1979; 95: 380-8.

21 Simpura J. Kuka Suomessa juo ja kuinka paljon? (Who drinks in Finland and how much?). Duodecim 1979; 95: 342-4.

22 Jaakkola $M$, Sillanaukee $P$, Suomalainen $H$, Koivula $T$, Nordback I. Effect of a high dose of ethanol on serum pancreatic enzymes in young healthy adults. $A m \mathcal{F}$ Gastroenterol 1992; 87: 461-4.

23 Jaakkola M, Frey T, Sillanaukee P, Koivula T, Nordback I. Evidence for regular pancreatic acinar cell injury after longterm heavy drinking. Hellenic foumal of Gastroenterology 1992; 5 (suppl 1992): 136.

24 Ranson JHC, Rifkind KM, Turner JW. Prognostic signs and non-operative peritoneal lavage in acute pancreatitis. Surg

25 Statiani B, Stone H. Predictability of present outcome and future recurrence in acute pancreatitis. Arch Surg 1979; 114 $711-6$. 